\title{
Mediastinal yolk sac tumour mimicking pericardial effusion
}

\author{
HASSAN CHAMSI-PASHA, ALAN BERNSTEIN \\ From the Department of Thoracic Medicine, University of Manchester Medical School, Hope Hospital, Salford
}

In this report we present a case of primary yolk sac tumour of the anterior mediastinum in which two dimensional echocardiography showed an extracardiac mass simulating a large pericardial effusion. Mediastinal yolk sac tumour is a rare germ cell neoplasm affecting mainly young men.' The most common presenting symptoms are dyspnoea, cough, and chest pain. ${ }^{2}$ The prognosis is usually poor, though in this case complete resolution of the tumour has been achieved.

\section{Case report}

A 26 year old man was referred with a six week history of cough, dyspnoea, and weight loss $(12 \mathrm{~kg})$. On examination he was very ill and dyspnoeic at rest and he had tachycardia. His blood pressure averaged $110 / 70 \mathrm{~mm} \mathrm{Hg}$ with pulsus paradoxus of $20 \mathrm{~mm} \mathrm{Hg}$. The jugular venous pressure was raised $7 \mathrm{~cm}$. The apex beat was impalpable, heart sounds were very faint and there were signs of a left pleural effusion. The edge of the liver was palpable $4 \mathrm{~cm}$ below the right costal margin. His testes were not enlarged. Electrocardiography showed a sinus tachycardia and the plain chest radiograph showed a massive, homogeneous soft tissue shadowing in the anterior mediastinum obliterating the cardiac silhouette and displacing the trachea posteriorly (fig 1 ). There was a small left pleural effusion.

Two dimensional echocardiography was performed with a Hewlett-Packard Model 77020 real time phased array scanner. It showed a large space completely surrounding the heart with what was initially thought to be the fibrinous strands floating within the space (fig $2 a$ ). The heart chambers were not dilated and the heart did not show excessive cardiac motion (swinging), as is often seen in malignant or tuberculous pericardiac effusion. The appearances were those of a pericardial effusion but pericardial aspiration yielded no fluid.

A right mediastinotomy showed a large necrotic mass surrounding the heart, containing green gelatinous material. The pericardium was intact and no pericardial effusion was found. The histological appearance of biopsied material showed the tumour to be of germ cell type with features suggesting yolk sac tumour (endodermal sinus tumour). The tissue was strongly positive for $\alpha$ fetoprotein, confirming the diagnosis of yolk sac tumour. The serum $\alpha$ fetoprotein was substantially raised at $23600 \mathrm{U} / \mathrm{ml}$ (normal $<10 \mathrm{U} / \mathrm{ml}$ ).

Six courses of a combination of vinblastine, etoposide, and cisplatin were given, with partial resolution of the tumour

Address for reprint requests: Dr H Chamsi-Pasha, Hope Hospital, Salford M6 8HD.

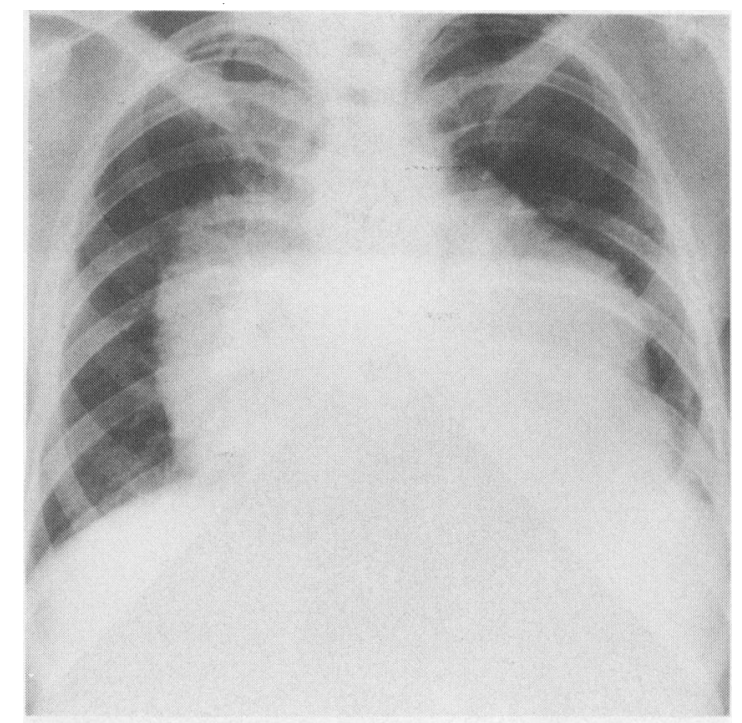

Fig 1 Chest radiograph showing a massive homogeneous shadowing obliterating the cardiac silhouette.

and a fall of the serum $\alpha$ fetoprotein concentration to $1000 \mathrm{U} /$ $\mathrm{ml}$. Six months later surgical resection of the residual tumour was performed but it was incomplete and was therefore followed by radiotherapy. Since then serum tumour markers have been undetectable ( $\alpha$ fetoprotein $<10 \mathrm{U} / \mathrm{ml}$ ). The patient is well two years after presentation.

\section{Discussion}

Yolk sac tumour (endodermal sinus tumour) is a subtype of germ cell tumour and a highly malignant neoplasm. In addition to presenting in ovaries and testes, the tumour has been detected at several extragonadal sites, including the presacral area, the anterior mediastinum, and the pineal gland. ${ }^{3}$ Primary yolk sac tumour of the anterior mediastinum is rare and carries a grave prognosis. ${ }^{34}$ Patients often present with advanced, bulky tumours that are unresectable. ${ }^{2}$

The differential diagnosis of mediastinal masses remains an important clinical problem and patients with a primary mediastinal tumour may present with a clinical and radiographic picture suggesting a primary cardiovascular abnormality. ${ }^{56}$ The standard radiological examinations may be inadequate to differentiate between cardiomegaly, pericardial effusion, and adjacent extracardiac mass. The patient 

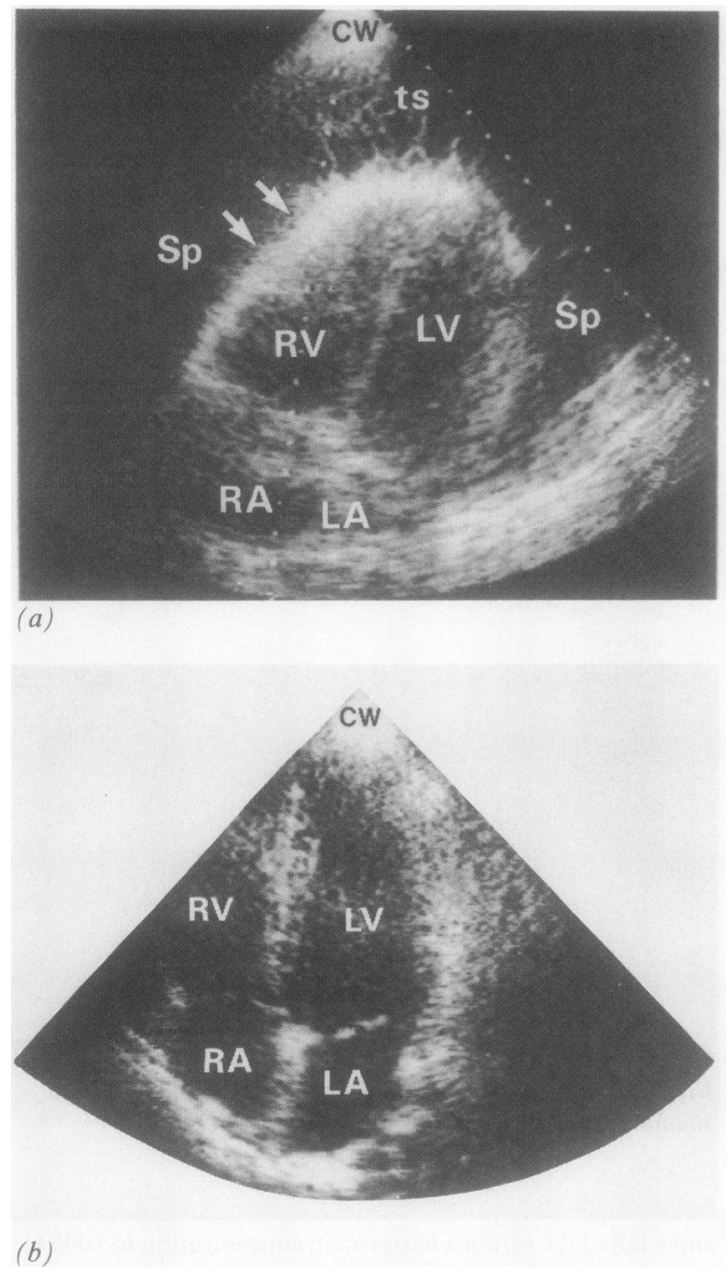

Fig 2 (a) Apical four chamber, two dimensional echocardiogram showing the yolk sac tumour surrounding the heart. (b) Apical four chamber view one year later showing resolution of the tumour. $C W$-chest wall structures; $S P-$ tumour space masquerading as pericardial effusion; TStumour strands; $R V$-right ventricle; $R A$-right atrium; $L V$-left ventricle; $L A$-left atrium. Arrows indicate the pericardium.

described had a clinical picture of cardiac tamponade and an abnormal cardiac silhouette. Two dimensional echocardiography showed what appeared to be a large pericardial effusion with fibrinous strands and raised the possibility of malignant pericardial effusion. The lesion was found at surgery to be a large necrotic tumour containing gelatinous material and surrounding the heart.

Various extracardiac tumours have been detected b区 echocardiography, including mediastinal and pericardia tumours, intrathoracic neoplasms, and pericardial cysts. Pericardial angiosarcoma simulating pericardial effusion on $\mathrm{M}$ mode echocardiography has been reported. ${ }^{8}$ Coplan et a described the value of two dimensional echocardiography iom the diagnosis of a pericardial mesothelioma masquerading as a benign pericardial effusion. An intrapericardial teratoma. resembled a pericardial effusion on echocardiography, ${ }^{10}$ wit b $^{1}$ a dense layer of echoes at the level of the aortic root. In this case the differentiation between an intrapericardial an extrapericardial lesion was difficult initially. In retrospect two features favoured an extrapericardial mass rather than $\mathrm{a}^{\mathrm{j}}$ pericardial effusion: firstly, absence of the excessive cardiac motion (swinging of the heart) that may be seen in malignantw pericardial effusion' and, secondly, the absence of bright echoes surrounding the outer edge of the clear space.

We believe that this is the first report in which the echocardiographic features of an extrapericardial yolk sat tumour surrounding the heart have been described.

We thank Drs Peter M Wilkinson and David C Beton fog their valuable help and Fiona Lamb for typing the manuscript.

\section{References}

1 Fox MA, Vix VA. Endodermal sinus (yolk sac) tumour of the anterior mediastinum. $A J R$ 1980;135:291-4.

2 Kuzur ME, Cobleigh MA, Greco FA, Einhorn LH, Oldham RK Endodermal sinus tumour of the mediastinum. Cance 1982;50:766-74.

3 Green DM. The diagnosis and treatment of yolk sac tumours in infants and children. Cancer Treat Rev 1983;10:265-88.

4 Israel A, Bosl GJ, Goldberg RB, Whitmore W Jr, Martini N. The results of chemotherapy for extragonadal germ-cell tumours iin the cisplatin era. J Clin Oncol 1985;3:1073-8.

5 Schloss M, Kronzon I, Gelber PM, Reed GE, Berger A. Cysti thymoma simulating constrictive pericarditis. $J$ Thora? Cardiovasc Surg 1975;70:143-6.

6 Oldham HN, Sabiston DC Jr, Durham NC. Primary tumours an cysts of the mediastinum presenting as cardiovascular abno malities. Arch Surg 1968;96:71-5.

7 Feigenbaum H. Echocardiography. 4th ed. Philadelphia: Lea and Febiger, 1986:558, 592.

8 Lin TK, Stech JM, Eckert WG, Lin JJ, Farha SJ, Hagan CTN Pericardial angiosarcoma simulating pericardial effusion by echocardiography. Chest 1978;73:881-3.

9 Coplan NL, Kennish AJ, Burgess NL, Deligdish L, Goldman ME Pericardial mesothelioma masquerading as a benign pericardif effusion. J Am Coll Cardiol 1984;4:1307-10.

10 Farooki ZQ, Hakimi M, Arciniegas E, Green EW. Echocardiographic features in a case of intrapericardial teratoma. $J$ Clin Ultrasound 1978;6:108-10. 